\title{
EXTENSIVE EXPERTISE IN ENDOCRINOLOGY Adrenal crisis
}

\author{
Bruno Allolio ${ }^{1,2,+}$ \\ ${ }^{1}$ Endocrine Unit, Department of Internal Medicine I, University Hospital Würzburg and \\ ${ }^{2}$ Comprehensive Heart Failure Center, University of Würzburg, 97080 Würzburg, Germany \\ ${ }^{\dagger} B$ Allolio is now at Department of Endocrinology and Diabetes, Medical University Hospital, University of \\ Würzburg, Oberdürrbacher Street 6, 97080 Würzburg, Germany
}

Correspondence should be addressed to B Allolio

Email

allolio_b@ukw.de

\begin{abstract}
Adrenal crisis is a life-threatening emergency contributing to the excess mortality of patients with adrenal insufficiency. Studies in patients on chronic replacement therapy for adrenal insufficiency have revealed an incidence of 5-10 adrenal crises $/ 100$ patient years and suggested a mortality rate from adrenal crisis of $0.5 / 100$ patient years. Patients with adrenal crisis typically present with profoundly impaired well-being, hypotension, nausea and vomiting, and fever responding well to parenteral hydrocortisone administration. Infections are the major precipitating causes of adrenal crisis. Lack of increased cortisol concentrations during infection enhances pro-inflammatory cytokine release and sensitivity to the toxic effects of these cytokines (e.g. tumour necrosis factor alpha). Furthermore, pro-inflammatory cytokines may impair glucocorticoid receptor function aggravating glucocorticoid deficiency. Treatment of adrenal crisis is simple and highly effective consisting of i.v. hydrocortisone (initial bolus of $100 \mathrm{mg}$ followed by $200 \mathrm{mg}$ over $24 \mathrm{~h}$ as continuous infusion) and $0.9 \%$ saline (1000 $\mathrm{ml}$ within the first hour). Prevention of adrenal crisis requires appropriate hydrocortisone dose adjustments to stressful medical procedures (e.g. major surgery) and other stressful events (e.g. infection). Patient education is a key for such dose adjustments but current education concepts are not sufficiently effective. Thus, improved education strategies are needed. Every patient should carry an emergency card and should be provided with an emergency kit for parenteral hydrocortisone self-administration. A hydrocortisone pen would hold a great potential to lower the current barriers to hydrocortisone self-injection. Improved patient education and measures to facilitate parenteral hydrocortisone self-administration in impending crisis are expected to significantly reduce morbidity and mortality from adrenal crisis.
\end{abstract}

\section{Introduction}

This narrative review on adrenal crisis is based on personal experience, own research, and comprehensive evaluation of the literature. It aims at contributing to more effectively combat morbidity and mortality from adrenal crisis.
Being the first to diagnose and treat adrenal insufficiency in a patient, after months of suffering with a multitude of futile investigations, is a most rewarding experience for any endocrinologist. Usually within $24 \mathrm{~h}$

Invited Author's profile

Bruno Allolio is Professor of Medicine at the University of Würzburg. He trained in Cologne in both clinical and experimental endocrinology. For postdoctoral studies, he worked at Bartholomew's Hospital, London, and at the NIH, Bethesda. His research interests focus on adrenal disorders, mineral metabolism and, more recently, also on hyponatraemia. He is a founding member of the European Network for the Study of Adrenal Tumours (ENSAT).

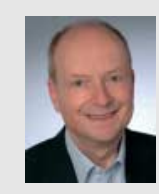

www.eje-online.org DOI: 10.1530/EJE-14-0824 (c) 2015 European Society of Endocrinology Printed in Great Britain
Published by Bioscientifica Ltd. 
after initiation of treatment, improvement in well-being is profound and often experienced by the patient as a miracle. This initial tremendous improvement in well-being has deceived expert physicians for some decades and led them to believe that treated patients with adrenal insufficiency lead a largely normal life with a normal life expectancy $(1,2,3)$. Only in recent years, it became evident that restoration of well-being remains incomplete $(4,5,6,7,8,9)$. The reasons for this incomplete recovery of well-being with current replacement regimens are still not fully understood and comprise among others a non-physiological glucocorticoid replacement with an altered diurnal rhythm of cortisol availability $(10,11,12,13,14)$, lack of DHEA $(15,16,17)$ and reduced adrenaline secretion from the adrenal medulla $(18,19)$. Even more recent is the discovery that mortality is also increased in patients with chronic adrenal insufficiency receiving standard replacement therapy $(20,21)$. This also affects patients with secondary adrenal insufficiency $(22,23,24)$. The more than twofold increased standardised mortality ratio in primary adrenal insufficiency is mainly due to cardiovascular causes and infections $(20,21)$.

Most importantly, adrenal crisis also contributes to excess mortality in patients with diagnosed chronic adrenal insufficiency. Adrenal insufficiency accounted for $15 \%$ of deaths in a Norwegian study of 130 deceased patients with Addison's disease, most probably reflecting the adrenal crisis (25). Two Swedish registry analyses in patients with Addison's disease reported 'endocrine causes' as responsible for the death in 12.6 and $8.3 \%$, respectively, also suggesting a role of adrenal crisis $(20,21)$. Similarly, among 1286 Swedish patients with hypopituitarism, adrenal crisis in response to acute stress and intercurrent illness was identified as an important cause of excess mortality (24).

Studies on the epidemiology of adrenal crisis give a consistent picture with an incidence between five and ten adrenal crises per 100 patient years in patients on standard replacement therapy. In a retrospective analysis of 444 patients with primary or secondary adrenal insufficiency, we observed a frequency of 6.3 adrenal crises/100 patient years (26). Reisch et al. (27) studied the incidence in adult patients with congenital adrenal hyperplasia and reported a frequency of 5.7 crises/100 patient years. More recently, Ritzel et al. (28) have investigated patients after bilateral adrenalectomy for Cushing's syndrome and found 9.3 crises/100 patient years. The largest analysis thus far was conducted via a postal survey by the UK Addison's disease Self Help Group in 841 patients from the UK, Canada,
Australia, and New Zealand indicating an incidence of eight crises per 100 patient years (29). However, these were all retrospective studies susceptible to various biases. In the first prospective study (30), we have recently observed 64 adrenal crises in 767.5 patient years (8.3 crises/100 patient years). Thus, approximately one in 12 patients will experience a life-threatening crisis in the coming year. This is a substantial percentage. Notably, there is an uneven distribution in the occurrence of crises, as some patients do not experience a single adrenal crisis for decades, while others have recurrent adrenal crises $(26,29)$. The reasons for this variability in crisis susceptibility are not understood.

Importantly, in this first prospective study, four patients died from adrenal crisis during 2 years of follow-up leading to a mortality rate from crisis of $0.5 / 100$ patient years. If confirmed in future studies, this would indicate an inacceptable death toll from adrenal crisis, as this condition is eminently treatable. Assuming a prevalence of adrenal insufficiency of 2.18-4.20/10 000 population (31) and a population of 507 million in the European Union (EU) (www.ec.europa.eu/eurostat), adrenal insufficiency affects between 110526 and 212940 people in the EU, leading to 5526 to 10647 expected deaths from adrenal crises in the coming decade in the EU, if the current situation prevails.

\section{A prismatic case}

A 40-year-old male with autoimmune Addison's disease on stable replacement therapy for 20 years developed diarrhoea and vomiting. His young daughters had recently suffered from gastroenteritis, which had been attributed to a Noro virus infection detected in their day care. The patient increased his oral dose of hydrocortisone, but his general health had markedly deteriorated the following day. His wife urged him to ask for professional help, but he declined indicating that he could manage the problem himself. He again increased his oral hydrocortisone dose. The following day there was evidence of cardiovascular failure and his wife called for emergency help. At arrival in hospital, the patient had no measurable blood pressure. Resuscitation was immediately started together with administration of i.v. hydrocortisone and rehydration. After transient stabilisation, cardiopulmonary resuscitation eventually remained unsuccessful and the patient died from adrenal crisis. Reportedly, one of his daughters later told her peers that she was responsible for the death of her father, as she had brought the infection to the family. 
A number of lessons can be derived from this case: gastroenteritis is a particular dangerous cause of adrenal crisis, oral hydrocortisone is frequently insufficient to reverse impending adrenal crisis, current education of patients is often not sufficiently effective, unwillingness to call for help (according to the patient's wife a feature of his personality) carries a huge risk and, at a certain point in time, damage from adrenal crisis will become irreversible no longer responding to medical measures. Finally, such an event is likely to have a life-long detrimental impact on the well-being of affected families.

This death in one of our patients, who had received repeated education during his outpatient visits and detailed written information concerning his disease, clearly also had an impact on my attitude to crisis prevention: I concluded that more effective efforts are needed to successfully combat such easily preventable mortality from adrenal crisis!

\section{Clinical presentation}

Patients with adrenal crisis typically present with severe hypotension and clinical evidence of hypovolaemia. Cardiovascular evaluation may find an abnormal electrocardiogram or even evidence of cardiomyopathy (32, 33, $34,35)$. Patients often appear exhausted and depressed. They report fatigue and a profound lack of energy. Adrenal crisis is often associated with anorexia, nausea, and vomiting $(26,29)$, frequently misinterpreted as evidence of gastrointestinal disease (36). Even more so, patients may complain of abdominal pain suggestive of early peritonitis (37). Fever is frequently observed, as in many instances adrenal crisis is triggered by infection. However, fever may also present as fever of unknown origin (38). At a later stage, patients can develop impaired cognition and somnolence (36).

In patients with undiagnosed adrenal insufficiency, there is usually a history of steadily declining general health over weeks to months or even over years with increasing fatigue, anorexia and weight loss. Patients with primary adrenal insufficiency develop the characteristic increased pigmentation related to hypersecretion of proopiomelanocortin-derived peptides, which may guide the diagnosis (31). A substantial subset of patients is diagnosed with psychiatric illness, in particular with anorexia nervosa $(36,39)$. Most patients have undergone extensive and repeated clinical investigations including endoscopy and imaging. Acute decompensation to fullblown crisis is then eventually triggered by a stressful event (e.g. surgery or infection).
A number of studies have investigated the causes of adrenal crisis in patients with already diagnosed chronic adrenal insufficiency $(26,27,28,29,40)$. Again infections, particularly gastroenteritis, are the most frequent causes. In addition, surgery, strenuous exercise, emotional stress and accidents contribute to adrenal insufficiency $(29,30)$. Notably, cessation of glucocorticoid therapy by the patient (or by the attending physician) may also precipitate adrenal crisis. In a recent study, in $\sim 10 \%$ of crises, patients were unable to identify a clear cause (30).

In my experience, development of an adrenal crisis usually takes several hours. However, there is substantial variation and a friend of mine who is an experienced paediatric endocrinologist insisted that, in children, adrenal crisis often develops very rapidly (Wolfgang Sippell, personal communication). Moreover, hypoglycaemia seems to be more common in children than in adults $(41,42)$. An orthopaedic colleague with longstanding adrenal insufficiency also confirmed that his adrenal crises occasionally evolved within an hour making it quite difficult for him to take the necessary preventive actions. In a survey of 37 patients who had experienced an adrenal crisis in the context of a prospective study (43), the median time from first symptoms to contacting health professionals was $135 \mathrm{~min}$ (range $5 \mathrm{~min}$ to 7 days) (unpublished data).

\section{Definition of adrenal crisis}

When we planned a prospective study on the incidence of adrenal crisis in patients with known adrenal insufficiency, we realised the need to define what actually constitutes an adrenal crisis. However, we found neither a textbook nor a paper providing such a definition, leaving us with the task to generate our own definition. We then decided to define adrenal crisis as a profound impairment of general health and at least two of the following conditions: hypotension (systolic blood pressure $<100 \mathrm{mmHg}$ ), nausea or vomiting, severe fatigue, hyponatraemia, hypoglycaemia and hyperkalaemia, triggering subsequent parenteral glucocorticoid administration. However, it turned out that in our prospective study hyponatraemia or hyperkalaemia contributed very little to the case finding.

Furthermore, we introduced a grading system depending on the setting required for treatment (grade 1: outpatient setting; grade 2 : in hospital care on a general ward; grade 3: admission to an intensive care unit); and outcome (grade 4: death from adrenal crisis).

This definition clearly is debatable. In particular, it may also be important to include the reversal of symptoms 
after administration of glucocorticoids. For example, one of my patients (adrenalectomised for a metastatic adrenocorticotrophin-secreting neuroendocrine tumour) showed no improvement in his severely impaired health and hypotension after i.v. glucocorticoid administration. He was later diagnosed with intestinal perforation. Thus, a slightly modified definition is given in Table 1 . I believe that this definition is highly useful and can serve as a pragmatic tool for future prospective investigations.

\section{Physiopathology of adrenal crisis}

The physiopathology of adrenal crisis is only partially understood. Hypotension can be explained by a lack of the permissive action of glucocorticoids on adrenergic receptors $(44,45,46,47)$ and by volume depletion caused by a lack of sodium and fluid retention due to missing mineralocorticoid activity $(31,48)$. Volume depletion may further be worsened by vomiting and diarrhoea.

It is well known that fever and infection lead to an increase in circulating cortisol levels in healthy subjects and, therefore, it is generally recommended that such an increase in cortisol levels should be mimicked by adjustment of the hydrocortisone dose in patients with adrenal insufficiency $(31,49)$. This course of action is a well-accepted standard of care, but the underlying mechanisms necessitating it are less clear. It has been proposed that glucocorticoids influence stress response by permissive, suppressive, stimulatory, and preparative actions (47). While a lack of permissive action of glucocorticoids is highly likely in patients with undiagnosed adrenal insufficiency leading to impaired activation

Table 1 Definition and grading of adrenal crisis (modified from (30)).

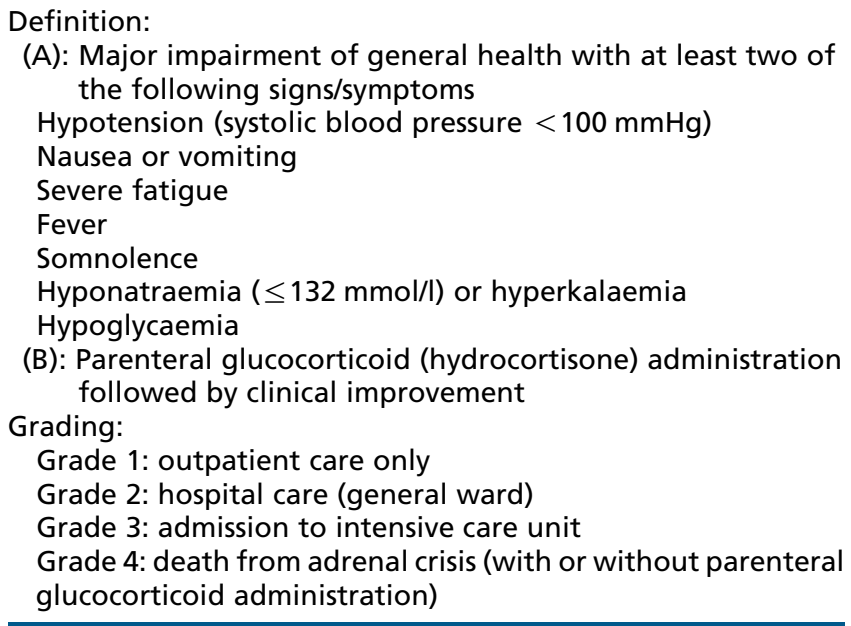

and responsiveness of the cardiovascular system, it is expected that adequate stable replacement therapy for chronic adrenal insufficiency ensures sufficient glucocorticoid activity for permissive action providing, for example, sufficient sensitivity to catecholamines during stress $(50,51)$. Thus, in patients with known adrenal insufficiency, the permissive action that is lacking is probably less, but the suppressive activity of increased glucocorticoid secretion is missing in adrenal crisis. This suppressive activity prevents the harmful effects of an overshooting immune defence $(52,53)$, probably primarily mediated via pro-inflammatory cytokines (47). Infection triggers the release of cytokines such as interleukin 1 (IL1), tumour necrosis factor alpha (TNF $\alpha$ ) and interleukin 6 (IL6), which physiologically stimulate the hypothalamus-pituitary-adrenal (HPA) axis leading to increased cortisol concentrations $(54,55)$. In turn, high glucocorticoid levels diminish cytokine release and action preventing their potential detrimental effects $(56,57)$. Accordingly, cytokines are increased in adrenalectomised experimental animals and doses of TNF $\alpha$ or IL1, which are readily survived in intact animals, prove to be fatal in glucocorticoid deficiency (58). Specifically, in a murine model of adrenal crisis (59), adrenalectomy greatly increased the sensitivity to the lethal effects of TNF $\alpha$. Adrenalectomised TNF receptor Ia and Ib null mice were resistant to the lethal effects of lipopolysaccharide as were mice treated with anti-TNF serum (59). Thus, considering $\mathrm{TNF} \alpha$ as a key mediator of adrenal crisis, glucocorticoid deficiency leads to both enhanced release of TNF $\alpha$ and enhanced sensitivity to TNF $\alpha$. Furthermore, experimental evidence indicates that $\mathrm{TNF} \alpha$ inhibits glucocorticoid receptor functions inducing a state of relative glucocorticoid resistance $(60,61)$. In summary, lack of suppressive glucocorticoid activity can trigger adrenal crisis via enhanced TNF $\alpha$ secretion, enhanced TNF $\alpha$ sensitivity and TNF $\alpha$-induced glucocorticoid resistance (Fig. 1).

For other causes of adrenal crisis (e.g. emotional stress and surgery), the underlying mechanisms may be similar, but have been much less studied. For example, surgery may increase the release of TNF $\alpha$ (62) and other cytokines (63) concurrent with the postoperative cortisol increase, and emotional stress may also induce glucocorticoid resistance (64).

\section{Treatment of adrenal crisis}

Suspected adrenal crisis requires immediate therapeutic action and, in undiagnosed adrenal insufficiency, treatment usually precedes the biochemical proof of diagnosis. 

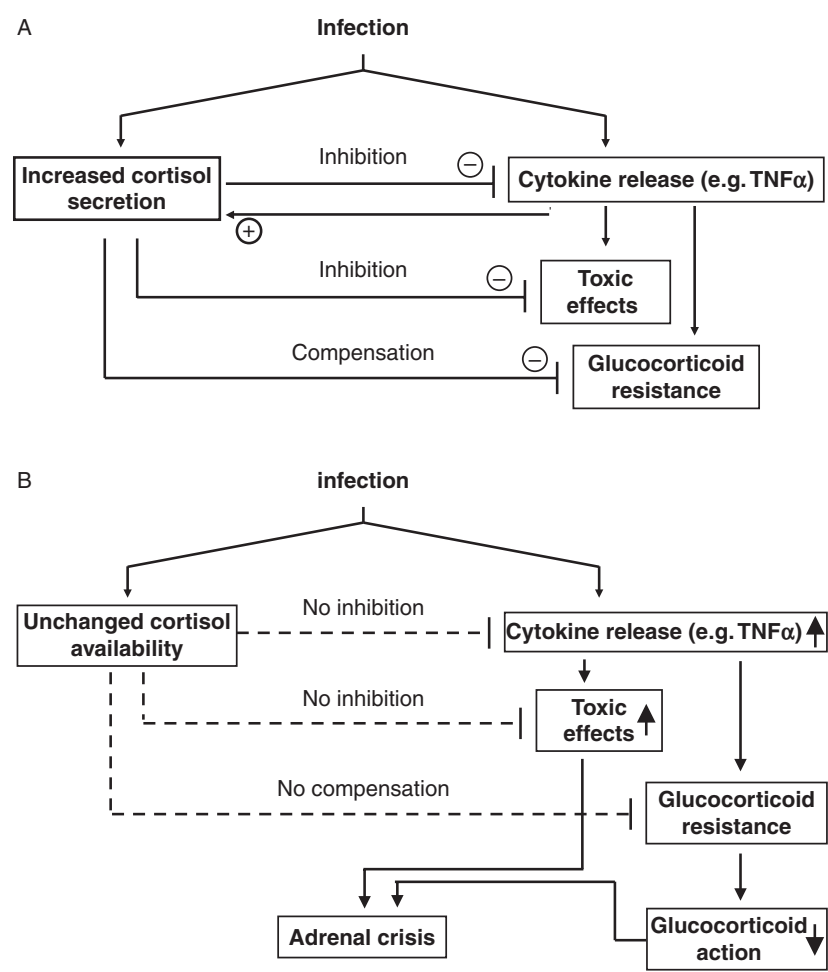

\section{Figure 1}

Glucocorticoid and cytokine interaction during major infection in patients with intact adrenals $(\mathrm{A})$ and patients with adrenal insufficiency on standard replacement therapy failing to adjust their hydrocortisone doses (B).

Treatment is simple. It consists of parenteral hydrocortisone (initially $100 \mathrm{mg}$ hydrocortisone as a bolus intravenously) and correction of hypovolaemia with isotonic saline (1000 $\mathrm{ml}$ isotonic saline within the first hour) (31, $36,48,49$ ) (Table 2). Only if hydrocortisone is not available, prednisolone or another synthetic glucocorticoid should be administered in an equivalent dose. Depending on the intercurrent illness, which precipitated the adrenal crisis, additional measures (e.g. antibiotics and thrombosis prophylaxis) are needed (49). This treatment is virtually uniformly successful leading to clinical recovery within $24 \mathrm{~h}$. If improvement does not occur in this time frame, alternative causes for the profoundly impaired health have to be considered again. As has been pointed out in the case vignette, there exists 'a point of no return' where even optimum patient care will no longer avert death from adrenal crisis. Furthermore, in case of longstanding untreated adrenal insufficiency presenting with confusion and somnolence, I have observed that full recovery can take several days or even up to 1 week.

\section{Prevention of adrenal crisis}

Physiological endogenous glucocorticoid secretion is highly flexible with rapid adjustments to unexpected needs. When collecting detailed salivary cortisol profiles in healthy students, we were struck by occasional unexplained sharp and high cortisol peaks. Upon questioning, we found out that one was caused by a late-night squash game and another by failing to catch a tram to the University hospital by just a few seconds. In the foreseeable future (if ever), no replacement therapy will be able to fully mimic this amazing adaptive potential of a healthy HPA axis. However, many stressors can be anticipated (e.g. elective surgery) and allow to adjust the glucocorticoid dose to the expected need, thereby preventing the occurrence of clinical deterioration and adrenal crisis. Table 3 gives an overview on treatment adjustments for medical procedures based on recommendations of the UK Addison's disease Self Help Group (49). It is important to understand herein the underlying concept. The recommended dose increase is not intended to mimic the median cortisol increase in healthy subjects during such procedures. Instead, it is intended to mimic the maximum cortisol increase, which may occur in euadrenal subjects triggered during these procedures, potentially induced by some unforeseen events (e.g. postoperative bleeding). Patients with intact adrenal function can respond immediately to such problems with an increase in adrenal cortisol output. By contrast, in adrenal insufficiency, additional glucocorticoids would only be given when clinical deterioration becomes evident. Until then, valuable time may have been lost to adjust the

Table 2 Treatment of adrenal crisis (modified from (49)).

Treatment

Hydrocortisone

Intravenous substitution of fluids

Depending on the severity of the crisis and on the intercurrent illness

\section{Dose/procedure}

$100 \mathrm{mg}$ bolus given immediately followed by $200 \mathrm{mg} /$ day as continuous infusion or frequent i.v. (or i.m.) boluses ( $50 \mathrm{mg}$ ) every $6 \mathrm{~h}$ $1000 \mathrm{ml}$ of $0.9 \%$ sodium chloride during the first $60 \mathrm{~min}$, further fluid administration $(0.9 \%$ sodium chloride) guided by individual patient needs as assessed clinically or by central venous pressure; frequent haemodynamic monitoring to avoid fluid overload; measurement of serum electrolytes

Admission to the intensive care or high-dependency unit; low-dose heparin; antibiotic treatment 
Table 3 Hydrocortisone adjustments for medical procedures (modified from (49)).

\section{Procedure}

Major surgery

Labour and vaginal birth

Minor surgery and major dental surgery

Invasive bowel procedures requiring laxatives

Dental procedure

Minor procedure

\section{Preoperative needs}

Start hydrocortisone infusion

(100 mg over $12 \mathrm{~h}$ ) just before anaesthesia

Start hydrocortisone infusion (100 mg hydrocortisone over $12 \mathrm{~h}$ ) at onset of labour

$100 \mathrm{mg}$ hydrocortisone before anaesthesia given as a bolus intramuscularly or subcutaneously or as hydrocortisone infusion for the duration of surgery

Hospital admission overnight with $100 \mathrm{mg}$ hydrocortisone intramuscularly or subcutaneously and fluid (isotonic saline), repeat dose before start of procedure Extra morning dose $1 \mathrm{~h}$ before surgery

Usually not required

\section{Postoperative needs}

Continue hydrocortisone infusion $(100 \mathrm{mg}$ over $12 \mathrm{~h}$ ) until able to eat and drink. Then double oral dose for $48+h$, then taper to normal dose

Continue hydrocortisone infusion until delivery (100 mg over $12 \mathrm{~h}$ ). Double oral dose for 24-48 $\mathrm{h}$ after delivery, then taper to normal dose

Double oral dose for $24 \mathrm{~h}$, then return to normal dose

Double oral dose for $24 \mathrm{~h}$, then return to normal dose

Double oral dose for $24 \mathrm{~h}$, then return to normal dose

Extra dose (e.g. $20 \mathrm{mg}$ hydrocortisone) if symptoms persist hydrocortisone dose to the increased need. For that reason, dose adjustments aim at the upper limit of the normal variation to cover such unexpected needs. The short-lived glucocorticoid excess for the majority of patients associated with this strategy apparently carries no significant risks $(50,51,65)$.

In emotional or mental stress, I recommend minor dose increases (e.g. $10 \mathrm{mg}$ as an additional dose). For example, in case of a written or oral examination or appearance in court, the additional dose should be taken $1 \mathrm{~h}$ before the event. Some patients report a need for a dose increase in strenuous exercise and such a dose increase is mandatory in otherwise sedentary subjects before exhaustive physical exercise (e.g. a mountain tour for several hours in the unprepared). As a rule of thumb, I am rather liberal concerning minor event-related dose increases and more focused on avoiding chronic over-replacement during standard treatment (e.g. $30 \mathrm{mg}$ hydrocortisone or more). Certain drugs enhance (e.g. mitotane, carbamazepine, St Johns wort, and rifampicin) or decrease (grapefruit juice and ritonavir) cortisol metabolism via induction or inhibition of CYP3A4 respectively $(66,67,68)$. Here the dose needs to be adjusted accordingly.

As infections are the most frequent cause of adrenal crisis $(24,26,29,69)$, it has been suggested that the patient doubles the hydrocortisone dose if the body temperature increases above $38^{\circ} \mathrm{C}$ and triples the dose above $39^{\circ} \mathrm{C}$. This dose is maintained as long as the fever persists and rapidly (within 1-2 days) reduced to the standard replacement dose after recovery. Gastroenteritis poses a particularly high risk $(26,29)$, as glucocorticoid availability may be compromised by vomiting and diarrhoea, while the demand is clearly increased. Thus, early parenteral hydrocortisone (100 mg subcutaneously) is strongly recommended either via self-administration or by a physician. This dose may need to be repeated and health-care professionals should be involved early for clinical assessment. Similarly, in severe infection (e.g. pneumonia) with altered cognition, early parenteral hydrocortisone and medical help are warranted (Table 4).

A particularly troubling cause of adrenal crisis is cessation of hydrocortisone therapy by the patient (or by the attending physician!). Careful education of the patient and his relatives is essential. There should be a low threshold for evaluation of a possible psychiatric illness in patients with evidence of poor compliance.

It has been suggested that patients today are at a greater risk of adrenal crisis, because they have less of a 'cushion' of excess circulating cortisol with a standard daily dose of $20 \mathrm{mg}$ hydrocortisone compared with the old-fashioned standard dose of $30 \mathrm{mg}$ hydrocortisone (29). However, there is no scientific evidence for such a protective 'cushion' effect. Instead, chronic over-replacement may rather increase the susceptibility to infection and thereby increase the risk of adrenal crisis (69).

\section{Patient education}

For obvious reasons, patient education is considered essential for crisis prevention, although its efficacy has 
Table 4 Dose adjustments in non-procedural stressful events.

\author{
Fever $>38^{\circ} \mathrm{C}$ \\ Fever $>39^{\circ} \mathrm{C}$
}

Gastroenteritis with vomiting and/or diarrhoea

Severe infection (e.g. pneumonia/with altered cognition)

Major emotional or mental stress (e.g. death of

a close relative, major university examination)

Exhaustive strenuous exercise

not been well studied. Furthermore, standardised patient education has not yet become a widely available tool in the care of patients with adrenal insufficiency, but has been demonstrated to increase knowledge concerning the disease (70).

As most physicians very rarely encounter an adrenal crisis, they frequently fail to act adequately. There are numerous reports from our patients and others (71) that physicians ignored emergency cards or failed to give parenteral hydrocortisone despite the patient presenting the emergency kit. Thus, I occasionally have given my patients a written text to be signed by any such future emergency physician. It states that the patient has communicated the presence of impending crisis, has shown the emergency card, and the emergency kit. By signature, the physician would thus attest that this evidence was presented, thereby documenting malpractice, if refusing to administer glucocorticoids. I reasoned that asking for the signature would greatly facilitate hydrocortisone administration.

As a consequence of these frequently encountered problems, the essential principle of crisis prevention can be stated as follows:

The well-informed patient (or his/her relative) guides the poorly informed health-care professional!

If so, it becomes mandatory that the patient should indeed be well informed and able to deliver such guidance. However, it has been shown that, despite repeated verbal education, a high percentage of patients $(46 \%)$ were not sufficiently skilled in coping with physical stress (72). This finding has been confirmed in a more recent investigation including 338 patients with adrenal insufficiency (73). A patient-specialist contact occurring only once a year is, therefore, unlikely to guarantee sufficient education. Thus, the development of improved education concepts remains a major task in future crisis prevention.

Every patient must be provided with an emergency card $(31,48,49)$ and I consider the newly designed
Double the daily hydrocortisone dose until recovery, then return to standard dose within 1-2 days

Triple the daily hydrocortisone dose until recovery, then return to standard dose within 2 days

Early parenteral hydrocortisone (100 mg subcutaneously or intramuscularly); to be repeated after $6-12 \mathrm{~h}$

Early parenteral hydrocortisone (100 mg subcutaneously or intramuscularly); to be repeated after 6-12 h (49) until recovery

Addition of $10-20 \mathrm{mg}$ hydrocortisone to the standard replacement dose

Add $10 \mathrm{mg}$ hydrocortisone 30-60 min before the exercise

European bilingual card a major advantage (74). In addition, every patient should have an emergency set (or two) consisting of $100 \mathrm{mg}$ hydrocortisone for parenteral administration. This injectable hydrocortisone allows immediate action by an attending health-care professional. However, every patient should also be able to self-administer parenteral hydrocortisone and close relatives should also be trained $(29,70)$. There is ample evidence that provision with injectable hydrocortisone is incomplete $(29,30)$ and that many patients provided with hydrocortisone for self-administration fail to use it, when needed $(29,75)$. Thus, in our unit, training for selfadministration of hydrocortisone has been prioritised in patient education. Importantly, we have recently demonstrated that s.c. hydrocortisone is rapidly absorbed with only a short delay compared with i.m. injection (76). Patients clearly prefer s.c. over i.m. injection, as would I. Reducing barriers to self-injection are most important in my view and the ease of s.c. injection far outweighs the short delay (11 min) in reaching concentrations above $1000 \mathrm{nmol} / 1$ (22 min compared with $11 \mathrm{~min}$ after i.m. injection) (76). This small time difference compares very favourably with current time lines from contacting health professionals until their eventual hydrocortisone injection in impending crisis (43). In fact, in my view, a clearly bigger problem is related to the current emergency sets, which often are not simple enough for rapid and easy handling by an already compromised patient. Accordingly, some patients have reported that the speed of development of their crisis had taken them by surprise, so that they were too weak to prepare the injection by the time they realised that they needed it (29). Thus, only the availability of a hydrocortisone pen will fully remove current delays in timely parenteral hydrocortisone selfadministration. As industry is reluctant to develop such a device, public funding is needed. This approach has been apparently successful in the case of adrenaline autoinjectors for anaphylaxis. 
In conclusion, reduction of morbidity and elimination of mortality from adrenal crisis should become a top priority for adrenal endocrinologists aiming at a 50\% reduction in crisis-related deaths within the following 10 years. To this end, it will be helpful to better understand the physiopathology of adrenal crisis to define optimum dose adjustments. Furthermore, patient education must move forward to a structured and quality-controlled approach offered to every single patient. Hydrocortisone self-administration is a critical part of patient education and would be greatly facilitated by the availability of a hydrocortisone pen. Public funding may be needed to make such a pen become a reality. Implementing these key measures will undoubtedly help to achieve a substantial reduction in mortality from adrenal crisis.

\section{Declaration of interest}

The author declares that there is no conflict of interest that could be perceived as prejudicing the impartiality of the review.

\section{Funding}

This research did not receive any specific grant from any funding agency in the public, commercial or not-for-profit sector.

\section{Acknowledgements}

The author is grateful to Stefanie Hahner and Martin Fassnacht, Würzburg and Wiebke Arlt, Birmingham, for critical review of the manuscript. The author also thanks Cindy Hofmann for excellent secretarial help.

\section{References}

1 Bondy P. Disorders of the adrenal cortex. In Williams' Textbook of Endocrinology, 7th edn, pp 816-890. Eds J Wilson \& DW Foster. 1985.

2 Nelson D. Diagnosis and treatment of Addison's disease. In Endocrinology, pp 1193-1201. Eds L Degroot, GF Cahiill \& L Martini, New York, NY: Grune and Stratton, 1979.

3 Mason AS, Meade TW, Lee JA \& Morris JN. Epidemiological and clinical picture of Addison's disease. Lancet 19682 744-747. (doi:10.1016/ S0140-6736(68)90948-3)

4 Lovas K, Loge JH \& Husebye ES. Subjective health status in Norwegian patients with Addison's disease. Clinical Endocrinology 200256 581-588. (doi:10.1046/j.1365-2265.2002.01466.x)

5 Thomsen AF, Kvist TK, Andersen PK \& Kessing LV. The risk of affective disorders in patients with adrenocortical insufficiency. Psychoneuroendocrinology 200631 614-622. (doi:10.1016/j.psyneuen.2006.01.003)

6 Hahner S, Loeffler M, Fassnacht M, Weismann D, Koschker AC, Quinkler M, Decker O, Arlt W \& Allolio B. Impaired subjective health status in 256 patients with adrenal insufficiency on standard therapy based on cross-sectional analysis. Journal of Clinical Endocrinology and Metabolism 200792 3912-3922. (doi:10.1210/jc.2007-0685)

7 Erichsen MM, Lovas K, Skinningsrud B, Wolff AB, Undlien DE, Svartberg J, Fougner KJ, Berg TJ, Bollerslev J, Mella B et al. Clinical, immunological, and genetic features of autoimmune primary adrenal insufficiency: observations from a Norwegian registry. Journal of Clinical Endocrinology and Metabolism 200994 4882-4890. (doi:10.1210/ jc.2009-1368)

8 Oksnes M, Bensing S, Hulting AL, Kampe O, Hackemann A, Meyer G, Badenhoop K, Betterle C, Parolo A, Giordano R et al. Quality of life in European patients with Addison's disease: validity of the diseasespecific questionnaire AddiQoL. Journal of Clinical Endocrinology and Metabolism 201297 568-576. (doi:10.1210/jc.2011-1901)

9 Tiemensma J, Andela CD, Kaptein AA, Romijn JA, van der Mast RC, Biermasz NR \& Pereira AM. Psychological morbidity and impaired quality of life in patients with stable treatment for primary adrenal insufficiency: cross-sectional study and review of the literature. European Journal of Endocrinology 2014171 171-182. (doi:10.1530/ EJE-14-0023)

10 Newell-Price J, Whiteman M, Rostami-Hodjegan A, Darzy K, Shalet S, Tucker GT \& Ross RJ. Modified-release hydrocortisone for circadian therapy: a proof-of-principle study in dexamethasone-suppressed normal volunteers. Clinical Endocrinology 200868 130-135. (doi:10.1111/j.1365-2265.2007.03011.x)

11 Debono M, Ross RJ \& Newell-Price J. Inadequacies of glucocorticoid replacement and improvements by physiological circadian therapy. European Journal of Endocrinology 2009160 719-729. (doi:10.1530/ EJE-08-0874)

12 Hahner S \& Allolio B. Therapeutic management of adrenal insufficiency. Best Practice \& Research. Clinical Endocrinology \& Metabolism 200923 167-179. (doi:10.1016/j.beem.2008.09)

13 Johannsson G, Nilsson AG, Bergthorsdottir R, Burman P, Dahlqvist P, Ekman B, Engstrom BE, Olsson T, Ragnarsson O, Ryberg M et al. Improved cortisol exposure-time profile and outcome in patients with adrenal insufficiency: a prospective randomized trial of a novel hydrocortisone dual-release formulation. Journal of Clinical Endocrinology and Metabolism 201297 473-481.

14 Oksnes M, Bjornsdottir S, Isaksson M, Methlie P, Carlsen S, Nilsen RM, Broman JE, Triebner K, Kampe O, Hulting AL et al. Continuous subcutaneous hydrocortisone infusion versus oral hydrocortisone replacement for treatment of addison's disease: a randomized clinical trial. Journal of Clinical Endocrinology and Metabolism 201499 1665-1674.

15 Arlt W, Callies F, van Vlijmen JC, Koehler I, Reincke M, Bidlingmaier M, Huebler D, Oettel M, Ernst M, Schulte HM et al. Dehydroepiandrosterone replacement in women with adrenal insufficiency. New England Journal of Medicine 1999341 1013-1020. (doi:10.1056/ NEJM199909303411401)

16 Hunt PJ, Gurnell EM, Huppert FA, Richards C, Prevost AT, Wass JA, Herbert J \& Chatterjee VK. Improvement in mood and fatigue after dehydroepiandrosterone replacement in Addison's disease in a randomized, double blind trial. Journal of Clinical Endocrinology and Metabolism 200085 4650-4656.

17 Gurnell EM, Hunt PJ, Curran SE, Conway CL, Pullenayegum EM, Huppert FA, Compston JE, Herbert J \& Chatterjee VK. Long-term DHEA replacement in primary adrenal insufficiency: a randomized, controlled trial. Journal of Clinical Endocrinology and Metabolism 200893 400-409. (doi:10.1210/jc.2007-1134)

18 Merke DP, Chrousos GP, Eisenhofer G, Weise M, Keil MF, Rogol AD, Van Wyk JJ \& Bornstein SR. Adrenomedullary dysplasia and hypofunction in patients with classic 21-hydroxylase deficiency. New England Journal of Medicine 2000343 1362-1368. (doi:10.1056/ NEJM200011093431903)

19 Zuckerman-Levin N, Tiosano D, Eisenhofer G, Bornstein S \& Hochberg Z. The importance of adrenocortical glucocorticoids for adrenomedullary and physiological response to stress: a study in isolated glucocorticoid deficiency. Journal of Clinical Endocrinology and Metabolism 200186 5920-5924. (doi:10.1210/jcem.86.12.8106)

20 Bergthorsdottir R, Leonsson-Zachrisson M, Oden A \& Johannsson G. Premature mortality in patients with Addison's disease: 
a population-based study. Journal of Clinical Endocrinology and Metabolism 200691 4849-4853. (doi:10.1210/jc.2006-0076)

21 Bensing S, Brandt L, Tabaroj F, Sjoberg O, Nilsson B, Ekbom A, Blomqvist $P$ \& Kampe O. Increased death risk and altered cancer incidence pattern in patients with isolated or combined autoimmune primary adrenocortical insufficiency. Clinical Endocrinology 200869 697-704. (doi:10.1111/j.1365-2265.2008.03340.x)

22 Rosen T \& Bengtsson BA. Premature mortality due to cardiovascular disease in hypopituitarism. Lancet 1990336 285-288. (doi:10.1016/ 0140-6736(90)91812-O)

23 Bates AS, Van't Hoff W, Jones PJ \& Clayton RN. The effect of hypopituitarism on life expectancy. Journal of Clinical Endocrinology and Metabolism 199681 1169-1172.

24 Burman P, Mattsson AF, Johannsson G, Hoybye C, Holmer H, Dahlqvist P, Berinder K, Engstrom BE, Ekman B, Erfurth EM et al. Deaths among adult patients with hypopituitarism: hypocortisolism during acute stress, and de novo malignant brain tumors contribute to an increased mortality. Journal of Clinical Endocrinology and Metabolism 201398 1466-1475. (doi:10.1210/jc.2012-4059)

25 Erichsen MM, Lovas K, Fougner KJ, Svartberg J, Hauge ER, Bollerslev J, Berg JP, Mella B \& Husebye ES. Normal overall mortality rate in Addison's disease, but young patients are at risk of premature death. European Journal of Endocrinology 2009160 233-237. (doi:10.1530/ EJE-08-0550)

26 Hahner S, Loeffler M, Bleicken B, Drechsler C, Milovanovic D, Fassnacht M, Ventz M, Quinkler M \& Allolio B. Epidemiology of adrenal crisis in chronic adrenal insufficiency: the need for new prevention strategies. European Journal of Endocrinology 2010162 597-602. (doi:10.1530/EJE-09-0884)

27 Reisch N, Willige M, Kohn D, Schwarz HP, Allolio B, Reincke M, Quinkler M, Hahner S \& Beuschlein F. Frequency and causes of adrenal crises over lifetime in patients with 21-hydroxylase deficiency. European Journal of Endocrinology 2012167 35-42. (doi:10.1530/EJE-12-0161)

28 Ritzel K, Beuschlein F, Mickisch A, Osswald A, Schneider HJ, Schopohl J $\&$ Reincke M. Clinical review: outcome of bilateral adrenalectomy in Cushing's syndrome: a systematic review. Journal of Clinical Endocrinology and Metabolism 201398 3939-3948. (doi:10.1210/ jc. 2013-1470)

29 White K \& Arlt W. Adrenal crisis in treated Addison's disease: a predictable but under-managed event. European Journal of Endocrinology 2010162 115-120. (doi:10.1530/EJE-09-0559)

30 Hahner S, Spinnler C, Fassnacht M, Burger-Stritt S, Lang K, Milovanovic D, Beuschlein F, Willenberg HS, Quinkler M \& Allolio B. High incidence of adrenal crisis in educated patients with chronic adrenal insufficiency - a prospective study. Journal of Clinical Endocrinology and Metabolism, 2014 (under review).

31 Arlt W \& Allolio B. Adrenal insufficiency. Lancet 2003361 1881-1893. (doi:10.1016/S0140-6736(03)13492-7)

32 Sherlock M, Gittoes NJ \& Arlt W. Adrenal crisis causing critical illness related reversible myocardial dysfunction. Clinical Endocrinology 2008 68 667-669. (doi:10.1111/j.1365-2265.2007.03061.x)

33 Afzal A \& Khaja F. Reversible cardiomyopathy associated with Addison's disease. Canadian Journal of Cardiology 200016 377-379.

34 Knowlton AI \& Baer L. Cardiac failure in Addison's disease. American Journal of Medicine $1983 \mathbf{7 4}$ 829-836. (doi:10.1016) 0002-9343(83)91074-4)

35 Conwell LS, Gray LM, Delbridge RG, Thomsett MJ \& Batch JA. Reversible cardiomyopathy in paediatric Addison's disease - a cautionary tale. Journal of Pediatric Endocrinology \& Metabolism 200316 1191-1195. (doi:10.1515/JPEM.2003.16.8.1191)

36 Allolio B, Lang K \& Hahner S. Addisonian crisis in a young man with atypical anorexia nervosa. Nature Reviews. Endocrinology 20117 115-121. (doi:10.1038/nrendo.2010.211)

37 Elasha HM, Anjum F \& Almalki MH. A young man with a dizzy spell and acute abdominal pain. Clinical Medicine 201313 520-521. (doi:10.7861/clinmedicine.13-5-520)
38 Mulder AH, Nauta S, Pieters GF \& Hermus AR. Addisonian crisis in patients with known adrenal insufficiency: the importance of early intervention. Nederlands Tijdschrift Voor Geneeskunde 2008152 1497-1500.

39 Tobin MV \& Morris AI. Addison's disease presenting as anorexia nervosa in a young man. Postgraduate Medical Journal 198864 953-955. (doi:10.1136/pgmj.64.758.953)

40 Omori K, Nomura K, Shimizu S, Omori N \& Takano K. Risk factors for adrenal crisis in patients with adrenal insufficiency. Endocrine Journal 200350 745-752. (doi:10.1507/endocrj.50.745)

41 Fischer JE, Stallmach T \& Fanconi S. Adrenal crisis presenting as hypoglycemic coma. Intensive Care Medicine 200026 105-108. (doi:10.1007/s001340050021)

42 DeVile CJ \& Stanhope R. Hydrocortisone replacement therapy in children and adolescents with hypopituitarism. Clinical Endocrinology 199747 37-41. (doi:10.1046/j.1365-2265.1997.2101025.x)

43 Hahner S, Hemmelmann N, Quinkler M, Beuschlein F, Spinnler C \& Allolio B. Time lines in the management of adrenal crisis - targets, limits and reality. Clinical Endocrinology, 2014.

44 Kalsner S. Mechanism of hydrocortisone potentiation of responses to epinephrine and norepinephrine in rabbit aorta. Circulation Research 196924 383-395. (doi:10.1161/01.RES.24.3.383)

45 Besse JC \& Bass AD. Potentiation by hydrocortisone of responses to catecholamines in vascular smooth muscle. Journal of Pharmacological and Experimental Therapeutics $1966 \mathbf{1 5 4} 224-238$.

46 Allolio B, Ehses W, Steffen HM \& Muller R. Reduced lymphocyte beta 2-adrenoceptor density and impaired diastolic left ventricular function in patients with glucocorticoid deficiency. Clinical Endocrinology 1994 40 769-775. (doi:10.1111/j.1365-2265.1994.tb02511.x)

47 Sapolsky RM, Romero LM \& Munck AU. How do glucocorticoids influence stress responses? Integrating permissive, suppressive, stimulatory, and preparative actions. Endocrine Reviews 200021 55-89.

48 Bancos I, Hahner S, Tomlinson J \& Arlt W. Diagnosis and management of adrenal insufficiency. Lancet Diabetes \& Endocrinology, 2014.

49 Husebye ES, Allolio B, Arlt W, Badenhoop K, Bensing S, Betterle C, Falorni A, Gan EH, Hulting AL, Kasperlik-Zaluska A et al. Consensus statement on the diagnosis, treatment and follow-up of patients with primary adrenal insufficiency. Journal of Internal Medicine 2014275 104-115. (doi:10.1111/joim.12162)

50 Udelsman R, Ramp J, Gallucci WT, Gordon A, Lipford E, Norton JA, Loriaux DL \& Chrousos GP. Adaptation during surgical stress. A reevaluation of the role of glucocorticoids. Journal of Clinical Investigation 198677 1377-1381. (doi:10.1172/JCI112443)

51 Salem M, Tainsh RE Jr, Bromberg J, Loriaux DL \& Chernow B. Perioperative glucocorticoid coverage. A reassessment 42 years after emergence of a problem. Annals of Surgery 1994219 416-425. (doi:10.1097/00000658-199404000-00013)

52 Tausk M. Hat die Nebenniere tatsächlich eine Verteidigungsfunktion? Das Hormon 19513 1-24.

53 Munck A, Guyre PM \& Holbrook NJ. Physiological functions of glucocorticoids in stress and their relation to pharmacological actions. Endocrine Reviews 19845 25-44. (doi:10.1210/edrv-5-1-25)

54 Besedovsky H, del Rey A, Sorkin E \& Dinarello CA. Immunoregulatory feedback between interleukin-1 and glucocorticoid hormones. Science 1986233 652-654. (doi:10.1126/science.3014662)

55 Mealy K, van Lanschot JJ, Robinson BG, Rounds J \& Wilmore DW. Are the catabolic effects of tumor necrosis factor mediated by glucocorticoids? Archives of Surgery 1990125 42-47 discussion 47-48. (doi:10.1001/archsurg.1990.01410130044006)

56 Barber AE, Coyle SM, Marano MA, Fischer E, Calvano SE, Fong Y, Moldawer LL \& Lowry SF. Glucocorticoid therapy alters hormonal and cytokine responses to endotoxin in man. Journal of Immunology 1993 150 1999-2006.

57 Morrow LE, McClellan JL, Conn CA \& Kluger MJ. Glucocorticoids alter fever and IL-6 responses to psychological stress and to lipopolysaccharide. American Journal of Physiology 1993264 R1010-R1016. 
58 Bertini R, Bianchi M \& Ghezzi P. Adrenalectomy sensitizes mice to the lethal effects of interleukin 1 and tumor necrosis factor. Journal of Experimental Medicine 1988167 1708-1712. (doi:10.1084/ jem.167.5.1708)

59 Koniaris LG, Wand G \& Wright TM. TNF mediates a murine model of Addison's crisis. Shock 200115 29-34.

60 Webster JC, Oakley RH, Jewell CM \& Cidlowski JA. Proinflammatory cytokines regulate human glucocorticoid receptor gene expression and lead to the accumulation of the dominant negative beta isoform: a mechanism for the generation of glucocorticoid resistance. PNAS 2001 98 6865-6870. (doi:10.1073/pnas.121455098)

61 Van Bogaert T, Vandevyver S, Dejager L, Van Hauwermeiren F, Pinheiro I, Petta I, Engblom D, Kleyman A, Schutz G, Tuckermann J et al. Tumor necrosis factor inhibits glucocorticoid receptor function in mice: a strong signal toward lethal shock. Journal of Biological Chemistry 2011286 26555-26567. (doi:10.1074/jbc.M110.212365)

62 Matsumoto ED, Margulis V, Tunc L, Taylor GD, Duchene D, Johnson DB, Pearle MS \& Cadeddu JA. Cytokine response to surgical stress: comparison of pure laparoscopic, hand-assisted laparoscopic, and open nephrectomy. Journal of Endourology 200519 1140-1145. (doi:10.1089/end.2005.19.1140)

63 Naito Y, Tamai S, Shingu K, Shindo K, Matsui T, Segawa H, Nakai Y \& Mori K. Responses of plasma adrenocorticotropic hormone, cortisol, and cytokines during and after upper abdominal surgery. Anesthesiology 199277 426-431. (doi:10.1097/00000542-199209000-00004)

64 Miller GE, Cohen S \& Ritchey AK. Chronic psychological stress and the regulation of pro-inflammatory cytokines: a glucocorticoidresistance model. Health Psychology 200221 531-541. (doi:10.1037) 0278-6133.21.6.531)

65 Zaghiyan KN, Murrell Z, Melmed GY \& Fleshner PR. High-dose perioperative corticosteroids in steroid-treated patients undergoing major colorectal surgery: necessary or overkill? American Journal of Surgery 2012204 481-486. (doi:10.1016/j.amjsurg.2011.09.036)

66 Kroiss M, Quinkler M, Lutz WK, Allolio B \& Fassnacht M. Drug interactions with mitotane by induction of CYP3A4 metabolism in the clinical management of adrenocortical carcinoma. Clinical Endocrinology 201175 585-591. (doi:10.1111/j.1365-2265.2011.04214.x)

67 Chortis V, Taylor AE, Schneider P, Tomlinson JW, Hughes BA, O'Neil DM, Libe R, Allolio B, Bertagna X, Bertherat J et al. Mitotane therapy in adrenocortical cancer induces CYP3A4 and inhibits $5 \alpha$-reductase, explaining the need for personalized glucocorticoid and androgen replacement. Journal of Clinical Endocrinology and Metabolism 201398 161-171.

68 Arlt W. The approach to the adult with newly diagnosed adrenal insufficiency. Journal of Clinical Endocrinology and Metabolism 200994 1059-1067.

69 Smans LC, Souverein PC, Leufkens HG, Hoepelman AI \& Zelissen PM. Increased use of antimicrobial agents and hospital admission for infections in patients with primary adrenal insufficiency: a cohort study. European Journal of Endocrinology 2013168 609-614.

70 Repping-Wuts HJ, Stikkelbroeck NM, Noordzij A, Kerstens M \& Hermus AR. A glucocorticoid education group meeting: an effective strategy for improving self-management to prevent adrenal crisis. European Journal of Endocrinology 2013169 17-22.

71 Wass JA \& Arlt W. How to avoid precipitating an acute adrenal crisis. BMJ 2012345 e6333. (doi:10.1136/bmj.e6333)

72 Flemming TG \& Kristensen LO. Quality of self-care in patients on replacement therapy with hydrocortisone. Journal of Internal Medicine 1999246 497-501. (doi:10.1046/j.1365-2796.1999.00538.x)

73 Harsch IA, Schuller A, Hahn EG \& Hensen J. Cortisone replacement therapy in endocrine disorders - quality of self-care. Journal of Evaluation in Clinical Practice 201016 492-498.

74 Grossman A, Johannsson G, Quinkler M \& Zelissen P. Perspectives on the management of adrenal insufficiency: clinical insights from across Europe. European Journal of Endocrinology 2013169 R165-R175. (doi:10.1530/EJE-13-0450)

75 Braatvedt GD, Newrick PG \& Corrall RJ. Patients' self administration of hydrocortisone. BMJ 1990301 1312. (doi:10.1136/bmj.301.6764.1312)

76 Hahner S, Burger-Stritt S \& Allolio B. Subcutaneous hydrocortisone administration for emergency use in adrenal insufficiency. European Journal of Endocrinology 2013169 147-154. (doi:10.1530/EJE-12-1057) 